\title{
AS REPRESENTAÇÕES SOCIAIS DE SI E DO SER PROFESSOR DE ALU- NOS DE LETRAS EM FORMAÇÃO INICIAL ${ }^{1}$
}

\author{
José Marcos Ernesto Santana de França* \\ Pollyanne Bicalbo Ribeiro ${ }^{* *}$
}

RESUMO: Este artigo teve como objetivo analisar e discutir as representações sociais de si e de ser professor de Língua Portuguesa em enunciados de alunos de sétimo semestre de um curso de Letras de uma universidade pública já em fase de estágio supervisionado. Assim, para alcançar tal intento, aplicamos um questionário semiestruturado aos referidos alunos para a coleta de dados e formação de um corpus de análise. A pesquisa, de caráter qualitativo-interpretativo, teve como arcabouço teórico os pressupostos bakhtinianos sobre o dialogismo e a Teoria das Representações Sociais (TRS) de Moscovici $(2012,2015)$ e os estudos sobre a formação de professores, baseando-nos em Schön (2000) e Tardif (2014). As análises nos apontaram que alguns alunos, apesar de já estarem no exercício do primeiro estágio supervisionado, têm uma representação de ser professor como uma profissão sacrificada, injustiçada, porém heroica e não têm uma representação de si como futuros professores atuantes no magistério.

PALAVRAS-CHAVE: Formação docente inicial; Representações sociais; Estágio supervisionado de Língua Portuguesa.

\section{Introdução}

A formação docente inicial em cursos de licenciatura plena tem sido, nos últimos tempos, bastante questionada e, por isso, se tornou objeto de pesquisas. A discussão se dá em um momento crítico para as licenciaturas, haja vista que a profissão docente está em descrédito e a procura por cursos de formação de professores está em queda.

\footnotetext{
${ }^{1}$ Este texto é um recorte de uma pesquisa de estágio pós-doutoral executada pelo autor na Universidade Federal do Ceará sob a supervisão da coautora.

${ }^{*}$ Doutor em Linguística pela Universidade Federal da Paraíba (UFPB). Realizou estágio pós-doutoral em Linguística Aplicada pela Universidade Federal do Ceará (UFC). Professor assistente de Língua Portuguesa do Departamento de Línguas e Literaturas e do Programa de Pós-Graduação em Letras da Universidade Regional do Cariri (URCA). Membro dos grupos de pesquisa DISCULTI e GERLIT.

${ }^{*}$ Doutora em Letras/Linguística Aplicada pela PUC Minas. Realizou estágio pós-doutoral em Linguística Aplicada pela Universidade de São Paulo (USP). Professora associada do Departamento de Letras Vernáculas, do PROFLETRAS e do Programa de Pós-Graduação em Linguística da Universidade Federal do Ceará (UFC). Líder do grupo de pesquisa GERLIT.
} 
Essa realidade quiçá seja o reflexo de uma série de fatores que tem contribuído para tal estado em que se encontram as licenciaturas e o desestímulo dos alunos e dos professores pela profissão docente. Segundo Aranha e Souza (2013), há fortes evidências, nos dias atuais, de que a profissão docente vive uma crise estrutural sem precedentes na história do nosso ensino. Para as autoras, entre os fatores que contribuem para esse quadro atual, o elemento-chave da sua explicação é o baixo valor do diploma de professor, sobretudo na educação básica, tanto no mercado de bens econômicos (salário) quanto no mercado de bens simbólicos (prestígio). Como consequência disso, já há uma escassez de professores para a demanda atual, que o Ministério da Educação (MEC) já contabiliza na casa dos 250 mil (ARANHA; SOUZA, 2013).

Diante desse quadro preocupante, nossa pesquisa abordou e investigou possíveis motivos que poderiam levar o alunado de um curso de Letras-Português de uma universidade pública a se sentir desestimulado diante da ideia de ser professor $^{2}$, mesmo que já esteja na fase do estágio. A motivação da pesquisa de estágio pós-doutoral, que resultou neste artigo, se deu, principalmente, a partir de comentários, queixas e críticas, às vezes ácidas, feitos pelos alunos já de sétimo semestre, em atividade de primeiro estágio supervisionado, sobre o curso e a instituição e o desestímulo em ser professor diante das adversidades encontradas na escola e em sala de aula durante a formação inicial.

Essas dificuldades, segundo os relatos, começam já com a procura de uma escola da rede pública que os aceitem como estagiários, pois há rejeições, tanto na rede municipal quanto na rede estadual. Apesar de o estágio ser algo obrigatório para a conclusão da graduação, algumas escolas veem com certa desconfiança a presença do estagiário circulando em seus espaços, porque expõem os trabalhos ali empreendidos, talvez isso possa motivar essa pouca receptividade por parte das escolas oficiais.

${ }^{2}$ Não queremos com isso dizer, ou passar a ideia, que esse desestímulo é uma particularidade apenas das IES públicas. 
Essas questões vieram à tona, sobretudo, nas aulas da disciplina Linguística Aplicada ao Ensino de Lingua Materna ${ }^{3}$, no sétimo semestre, onde algumas reflexões foram suscitadas mediante provocações motivadas por leituras situadas na temática da formação docente e de ser professor diante de tantas dificuldades das mais diversas ordens: como falta de orientação metodológica para a prática docente, desvalorização salarial do profissional docente, precarização das condições de trabalho, etc. Assim, ao adentrar nessa seara de conhecimento, que envolve a formação de futuros professores formadores, propomos (re)discutir, (re)pensar, transgredir, questionar o ensino/aprendizagem, a formação docente e a constituição identitária do profissional de línguas, do ser professor e a sua prática (o seu métier). Em vista disso, dentro do contexto da LA, buscou-se fazer a ponte, traçar uma ligação entre o que se discutia no âmbito dessa disciplina e o estágio de docência que eles estavam executando em paralelo, tentando estabelecer um processo de ação-reflexão-ação, nos moldes de Schön (2000), e a profissionalização docente e os saberes necessários ao desempenho do métier, a partir da proposta de Tardif (2014).

Para os fins da pesquisa, em específico, fizemos um recorte dentro do tema geral da formação de professores e traçamos as seguintes questões: que representações os alunos mobilizam sobre ser professor? Que representações os alunos mobilizam sobre si como professor? Que saberes um professor deve dominar para ser considerado um bom professor? Para obtermos as respostas a essas perguntas, aplicamos um questionário a 30 alunos do sétimo semestre do curso de licenciatura em Letras-Português, mas apenas 20 foram devolvidos ao pesquisador. Esses formulários compuseram o corpus de análise. Desse corpus, para os fins deste artigo e pelo espaço disponível próprio para este gênero textual, limitamonos a analisar 10 questionários, escolhidos de forma randômica para manter a maior imparcialidade possível.

De acordo com dados obtidos na pesquisa, pudemos fazer o seguinte levantamento do perfil dos alunos: dos 20 (vinte) informantes, apenas 1 (um) assinalou que estudou em 
escola privada; todos cursaram o ensino básico regular; e apenas 8 (oito) estavam cursando letras por convicção, ou seja, foi realmente a primeira opção. Dentre os vinte informantes, três já tinham experiência de sala de aula, sendo que dois ainda estavam na ativa e destes, um expressou que estava muito desestimulado e em dúvida se iria continuar na profissão após a conclusão do curso porque estava decepcionado com a desvalorização do professor pelos alunos e pela direção da escola. Essas informações corroboram o que Aranha e Souza dizem sobre os estudantes de cursos de licenciatura provirem de "escolarização básica mais precária", haja vista que a maioria absoluta dos informantes são provenientes de escola pública e com o agravante de que a "escolha" pelo curso de Letras não foi a primeira opção.

Para a análise, por sua vez, temos como fundamentação os aportes teóricos da: Teoria das Representações Sociais: Moscovici (2012, 2015), Marková (2006), Jodelet (2009), Ribeiro (2017), Matencio e Ribeiro (2009); da Teoria Dialógica do Discurso: Bakhtin/Volochinov, (2004); e da formação docente/de professores (crítico-reflexivo, relação teoria/prática, profissional): Schön (2000), Tardif (2014).

Esses autores e suas abordagens teóricas nos ajudaram a tentar entender e explicar porque os alunos se sentem tão desestimulados em relação ao curso e à futura profissão, assim como a complexa relação que há entre os saberes necessários à formação docente e o seu desempenho como futuro profissional a partir das representações sociais que o aluno tem de si como estagiário e do ser professor de língua. Em síntese, trata-se de analisar o discurso da formação docente a partir da ótica do sujeito-aluno em formação inicial por meio de suas representações sociais sobre a temática em foco.

O texto está assim estruturado: na primeira seção, apresentamos a Teoria das Representações Sociais articulada à Teoria Dialógica do Discurso; na segunda seção, discutimos a formação docente, o ser professor e os saberes envolvidos no métier, por fim, na terceira seção, analisamos os enunciados dos sujeitos-informantes, a partir do corpus colhido por meio de aplicação de formulário de entrevista a estudantes de sétimo semestre do curso de Letras-Português de uma universidade pública do interior do estado do Ceará, vivenciando o primeiro estágio supervisionado em turmas de ensino fundamental - séries finais. 


\section{A teoria das representações sociais: representações de si e do outro}

Nesta seção, apresentamos uma discussão em torno da Teoria das Representações Sociais (TRS) proposta por Moscovici (2012, 2015) aproximada da Teoria Dialógica do Discurso (TDD) proposta por Bakhtin/Volochinov (2004), visando, sobretudo, as contribuições dessa aproximação para refletir sobre a constituição identitária do professor na formação inicial. Interessa-nos analisar que representações sociais os sujeitos-alunos têm de si e do outro como professor e do métier docente.

Segundo Jodelet (2009), a teoria das representações sociais reapresenta um problema que já é, historicamente, de interesse de outras ciências humanas, como a história, a antropologia e a sociologia. Na perspectiva tomada e conceituada por Moscovici (2012), mesmo reconhecendo que o conceito não é de fácil apreensão, as representações sociais, sob o olhar da Psicologia Social, são propostas como uma teoria científica sobre os processos através dos quais os sujeitos em interação social constroem explicações sobre objetos sociais.

Para interpretar como os sujeitos-alunos do curso de Letras-Português de uma universidade pública reconstrói “a realidade cotidiana”, particularmente, aspectos concernentes a representações sobre si como futuros professores e sobre ser professor, partimos da premissa de que a formulação, a atualização e a modificação do repertório representacional intra/intergrupal se efetivam por via das interações. O "entendimento social” (cf. BAKHTIN/VOLOCHINOV, 2004) é essencialmente reflexivo e refratário, ou seja, ele deixa entrever tanto os traços ordinários dos sujeitos sociais como as (trans)formações.

O indivíduo, portanto, é constituído de material semiótico fruto da tessitura histórica, cultural e ideológica, ou seja, a maneira que o ser se apresenta aos outros, as suas representações identitárias é efeito das relações, das tensões e das mudanças sociais. Afinal, “onde existe diálogo, existe atividade humana. As palavras desejam ser ouvidas e, similarmente, as ideias - como eventos vivos - querem também ser entendidas e respondidas pelos outros, de acordo com suas perspectivas” (MARKOVÁ, 2006, p. 53).

As representações sociais, portanto, cumprem as funções de orientar, saber, justificar e identificar (ABRIC, 1986), elas interferem no nosso agir em sociedade, viabilizam a 
unidade entre membros, garantindo a organização de grupos sociais. Através do acervo representacional mobilizado dialogicamente nas interações, o sujeito, inscrito na condição de membro, poderá compor a sua representação identitária ora convergindo, ora divergindo das representações tomadas como referência.

Py (2000, 2004), ao analisar a dinâmica das representações sociais, salienta que há duas modalidades de representações: a de referência (RR) e a de uso (RU). As RR, mais estáveis, configurariam o repertório comum de um determinado grupo social; já as RU, mais dinâmicas, são reveladoras das singularidades, das trocas entre sujeitos sociais (MATENCIO; RIBEIRO, 2009). Lidamos com a tensão das forças dessas duas modalidades (força centrípeta e força centrífuga), avaliamos e atualizamos nosso acervo representacional a partir daquilo que é dado pela memória coletiva disponibilizada pelo nosso grupo de pertença e, a partir de processos reflexivos e refratários, conformamo-nos diante das crenças, tomadas de posicionamentos, opiniões, etc., interpretamos o mundo e nos inscrevemos nele, (re)velando, assim, nossas representações identitárias, constantemente (re)formuladas na teia discursiva.

A representação social é um conhecimento prático, por isso dá sentido aos eventos que nos são normais, forja as evidências da nossa realidade consensual e ajuda a construção social de nossa realidade (SÊGA, 2000). Em Moscovici (2015), a representação social é tratada como um fato psicossocial, daí o sujeito social não está dissociado do sujeito psicológico, pois o indivíduo só se constitui como sujeito de discurso na relação do $e$ com o outro, porque é justamente no imbricamento desses dois sujeitos que a relação com o objeto de discurso se estabelece (BAKHTIN; VOLOCHINOV, 2004).

A abordagem, em Moscovici (2015), é sobre o sujeito enquanto ser constituído numa posição social, o que o aproxima de uma perspectiva do sujeito situado do Círculo de Bakhtin, um sujeito sempre a ser preenchido (incompletude discursiva) constituído histórico-socialmente por práticas discursivas. O que define de fato o sujeito é a sua relação com o outro, haja vista que "no diálogo, os participantes se confirmam como co-autores e confirmam também suas participações nas realidades sociais” (MARKOVÁ, 2006, p. 124). O lugar que é conferido aos interlocutores é um espaço de representação social (ex: médico, 
pai, professor, motorista etc.), que é uma unidade apenas abstratamente, pois, na prática, é atravessada pela dispersão. Essa unidade que nos referimos é uma criação ideológica, por isso, podemos dizer que o sujeito é um acontecimento simbólico (eventicidade).

O sujeito, segundo Jodelet (2009), é tratado mais ou menos explicitamente, nas diferentes abordagens, seja como resposta elementar dos agregados que definem uma estrutura de representação, seja como lugar de expressão de uma posição social, seja como portador de significados circulantes no espaço social ou construídos na interação. Os dois posicionamentos de sujeito (TRS e TDD), a nosso ver, não se negam, pelo contrário, se imbricam na medida em que tanto um como outro o tomam como um lugar social, portanto, o sujeito se constitui sócio-historicamente por meio de representações.

Para a Linguística Aplicada (LA), interessa compreender o sujeito bistórico, social, situado, que revisitará seu acervo representacional concernente à figura docente na prática. $\mathrm{O}$ (futuro) professor, ao acessar o repertório representacional, poderá revelar expectativas, frustrações, saberes, sobre o ser docente e o métier que merecem ser tematizados nos empreendimentos teórico-metodológicos das agências formativas. Assim, considerar as representações sociais em práticas formativas é ação profícua para a revisão da organização curricular nas instituições educativas.

Segundo Moscovici (2015, p. 38), "O poder e a claridade peculiares das representações - isto é, das representações sociais - deriva do sucesso com que elas controlam a realidade de hoje através da de ontem e da continuidade que isso pressupõe." Em outros termos, as representações sociais, de acordo com o autor, exerce um poder, certamente sobre os sujeitos, que controla a maneira como eles veem a realidade, o outro e as coisas a ele pertencentes, e a julgam, avaliam segundo seus valores éticos e morais adquiridos, formados sócioculturalmente. Esse sistema simbólico que atravessa pensamento, conhecimento, crença e comunicação é efeito das capacidades representativas dos interlocutores (MARKOVÁ, 2006).

Isso faz com que as representações sociais do ser professor passem pelas crenças e experiências de vida e de vivência pelas quais passou o sujeito-aluno. Sendo assim, é preciso 
ampliar a discussão sobre a necessidade de identificar e analisar as representações na formação inicial docente.

Na seção seguinte, discutiremos sobre a formação docente e a profissão professor, como um métier, na relação com os saberes e a identidade.

\section{A formação docente e o ser professor como profissão: os saberes e a identidade}

Em relação ao saber docente, Tardif (2014) defende que o saber não se reduz, exclusiva ou principalmente, a processos mentais, cujo suporte é a atividade cognitiva dos indivíduos, mas é também um saber social que se manifesta nas relações complexas entre professores e alunos. Para esse autor, "Os saberes de um professor são uma realidade social materializada através de uma formação, de programas, de práticas coletivas, de disciplinas escolares, de uma pedagogia institucionalizada, etc., e são também, ao mesmo tempo os saberes dele" (TARDIF, 2014, p. 16).

Por isso é preciso “ $[. .$.$] situar o saber do professor na interface entre o individual e$ o social, entre o ator e o sistema, a fim de captar a sua natureza social e individual como um todo" (TARDIF, 2014, p. 16), na verdade, estamos situando o sujeito-professor(a) no bojo das representações sociais suscitadas por ele, posto que o ser não pode estar fora de uma realidade social. Essa realidade social faz parte de sua bagagem cultural e isso influencia o seu olhar sobre o mundo e, portanto, consequentemente, determina suas representações sociais que norteiam o seu fazer, mas que são constituídas e construídas no coletivo, nas "práticas coletivas".

Ao refletir sobre o processo de formação de professores, o referido autor argumenta que se deve levar em conta o conhecimento do trabalho dos professores, seus saberes cotidianos. Essa posição, assumida por Tardif (2014), põe em xeque a ideia tradicional de que os professores são apenas transmissores de saberes produzidos por outros e que apenas o conhecimento acadêmico é que deve ser considerado como "válido" porque científico em contraposição ao conhecimento do cotidiano, do senso comum. Nesse ponto, a posição de Tardif se coaduna com a linha de pensamento de Moscovici, ao valorizar o 
senso comum, visto que a sedimentação de novos conhecimentos advindos da esfera científica dependerá do que está dado, posto.

Particularmente no que diz respeito à prática formativa, o acervo representacional trazido pelo(a) aluno(a), RR, possibilitará a compreensão dos saberes cunhados no âmbito da graduação, RU. Nesse passo, Tardif (2014) propõe que docentes e discentes, pesquisadores e educadores unam teoria e prática, sejam todos pesquisadores e sujeitos de conhecimento. Os cursos de formação de professores precisam encontrar "[...] uma nova articulação e um novo equilíbrio entre os conhecimentos produzidos pelas universidades a respeito do ensino e os saberes desenvolvidos pelos professores em suas práticas cotidianas" (TARDIF, 2014, p. 23).

O discurso educacional (pedagógico) permeia o discurso do fazer docente (didático), nesse caso, ressoando como um interdiscurso, dando-lhe suporte teórico. Os saberes dos professores vão se constituindo e se construindo num processo dialógico entre os saberes provenientes de sua bagagem sociocultural e familiar e os acadêmicos provenientes de sua formação e seu próprio fazer pedagógico, ou seja, do exercício diário da profissão. Nesse sentido, é possível dizer que para ocorrer o processo avaliativo/reflexivo é preciso lidar, atualizar e modificar o acervo representacional. Ademais, o acesso às representações sempre se dá à luz do dialogismo, a partir das forças centrípetas e centrífugas, refletividade e refração de acordo com o Ciclo de Bakhtin.

É pertinente estabelecer uma relação entre o que propõe Tardif (2014) sobre os saberes docentes e a formação profissional e a chamada pedagogia reflexiva que defende a formação do profissional reflexivo, na perspectiva proposta por Schön (2000), na medida em que o primeiro defende que os conhecimentos que constituem os saberes docentes devem ser compreendidos na íntima relação com o trabalho.

O modelo de reflexão sugerido por Schön (2000) está baseado em dois construtos: a) a reflexão na ação consiste na reflexão antes de ocorrer a ação; b) a reflexão sobre a ação consiste na reflexão após a ocorrência da ação ou no meio da ação. Ou seja, o profissional reflexivo é aquele que se volta para o seu próprio fazer de forma reflexiva no decorrer do processo, da ação (ele para e pensa sobre a ação que está desenvolvendo), e isso o leva a 
conhecer na própria ação que faz. Segundo Silva (2013), os formadores de professores têm na atualidade como um grande desafio implementar programas voltados para a formação de um profissional crítico-reflexivo frente a sua prática e dentro de seu contexto históricosocial de atuação. Certamente, formar professores crítico-reflexivos que estejam em contínuo processo de leitura e releitura crítico-reflexiva sobre sua própria prática, os seus saberes e o seu contexto histórico-social é formar e possibilitar novas representações sociais de ser professor, de seu métier e do seu papel político-social.

Vemos que há uma preocupação com a "formação pessoal" tendo em vista a aquisição e o domínio de conhecimentos, focando o aspecto humano como um ponto central dessa formação atrelado à formação de um sujeito que reflita sobre a ética do seu próprio fazer dentro de uma dimensão que abranja o "contexto cultural, sócio-econômico e político". Essa questão passa pela formação do professor enquanto profissional da educação que não se restringe apenas à formação em Letras e do professor de LP.

Essa mudança de foco, certamente, mudaria a postura do sujeito em formação à medida que ele passasse a perceber-se em um processo que envolve o seu desenvolvimento, a "formação pessoal". Assim, ao sujeito em formação inicial devem ser dadas as condições necessárias para uma formação com bases teórico-científicas sólidas. Em vista disso, é preciso considerar que o desenvolvimento profissional "é um processo, não é algo linear, estático, os parâmetros, as variáveis, as representações são constantemente (re)avaliadas. Os profissionais se (trans)formam à medida que a relação com o trabalho, com os pares, com os recursos também se (trans)formam (RIBEIRO; LOUSADA, 2018, p. 42).

Como as autoras afirmam que o desenvolvimento profissional é um processo, acreditamos que a constituição identitária do professor também se dê num processo constitutivo; que a identidade docente vá se constituindo com o tempo, que a identificação com a profissão, o métier, vá sendo construída historicamente. Nesse percurso, certamente alguns percalços podem surgir, o que pode provocar reavaliações, e consequentemente novas representações, em relação ao ofício, de reafirmação ou de rejeição, provocadas pelas intempéries das adversidades do sistema, como é apontada por um dos sujeitos-alunos informantes de nosso corpus: "Ser professor nos dias atuais é antes de tudo um ato de resistência, 
principalmente quando se pensa no Ensino Básico. Tudo parece ir contra, baixo salário, condições de trabalho precárias, falta de investimento nas escolas, e bases ideológicas pra lá de conservadoras se pensarmos em debates atuais que são necessários". Esse cenário descrito pelo sujeito-aluno é, de fato, bastante desalentador e, por isso, nada motivador para que a profissão seja atraente para os jovens que pensem em ser professores(as); e para aqueles que já estão no processo de formação docente se sintam desmotivados a seguir a profissão após a formatura.

Essas questões e outras pertinentes sobre a formação e a identidade docentes é o que iremos analisar e discutir com base no corpus na seção seguinte.

\section{O que é ser professor? Que saberes dominar? Com a palavra, o futuro professor de} língua portuguesa

Nesta seção, analisaremos os enunciados dos sujeitos-alunos(as) extraídos das respostas de um questionário aplicado. $\mathrm{O}$ corpus a ser analisado aqui é um recorte das respostas dadas a duas questões específicas do questionário. Ele foi obtido com a aplicação do questionário ${ }^{4}$ a alunos(as) do sétimo semestre de um curso de Letras-Português licenciatura em fase de estágio supervisionado de uma universidade pública do interior do Estado do Ceará.

De acordo com o Projeto Pedagógico de Curso (PPC) da instituição, a "Prática de Ensino" deve ser ministrada sob a forma de Estágio Supervisionado, com uma carga horária de 210h, no qual há um acompanhamento sistemático dos discentes estagiários pelo docente supervisor, deve acontecer, preferencialmente, em unidades escolares públicas, onde os alunos vivenciam o cotidiano escolar, contribuindo para a renovação do ensino do português. Esse preceito segue o que propõe o Art. 13, \ $6^{\circ}$ da Resolução CNE n ${ }^{\circ} 2$ de 01 de julho de 2015. Com fundamento neste ato formativo e a Resolução nº 24/98-CEPE, de

\footnotetext{
${ }^{4}$ Como já observamos, a pesquisa é um pouco mais ampla. Em vista disso, fizemos um recorte nos dados do corpus que obtivemos e trazemos para este texto apenas três das questões que compõem o questionário. Elas são pontuais e atendem a um ponto específico da pesquisa.
} 
12/11/1998, o Estágio pretende oportunizar ao aluno a observação, a pesquisa, o planejamento, a execução e a avaliação do fazer pedagógico imprescindível à formação do futuro profissional.

O Estágio Supervisionado, segundo o PPC, é um dos componentes do currículo do curso, é parte obrigatória da formação acadêmico-profissional do licenciando, é uma atividade específica intrinsicamente articulada com a prática e com as demais atividades do trabalho acadêmico. Nesse sentido, o ementário da disciplina Estágio Supervisionado I, prever o seguinte: "Prática de ensino de Língua Portuguesa em escolas de Ensino Fundamental II: observação, participação e regência de classe.” Na prática, o estágio é cumprido em dupla e cada membro da dupla deve ministrar 50\% da regência (30h/a), e ao final, é apresentado um relatório individualmente.

Nosso objetivo foi identificar que representações o sujeito-aluno mobiliza sobre o ser professor, sobre si como professor e sobre os saberes que um professor deveria dominar em seu métier. É o que passaremos a analisar nos enunciados das respostas dos dez sujeitos-alunos (SA) selecionadas.

\section{Qual a imagem que você tem de ser professor(a)?}

SA1: Ser professor nos dias atuais é antes de tudo um ato de resistência, principalmente quando se pensa no Ensino Básico. Tudo parece ir contra, baixo salário, condições de trabalho precárias, falta de investimento nas escolas, e bases ideológicas pra lá de conservadoras se pensarmos em debates atuais que são necessários. A sociedade enxerga o professor como um super herói que deve fazer tudo sozinho, porém enxergo essa questão com um pouco mais de complexidade, o professor não tem condições de fazer sozinho com que a educação dê certo, sem investimentos e a ajuda da sociedade, família e governo, enquanto todos não tiverem essa consciência ser professor continuará sendo uma profissão que carrega nas costas o peso de toda uma sociedade.

SA2: Vejo-me como alguém que futuramente terá um papel muito importante na sociedade bem como uma grande responsabilidade na tarefa de educar.

SA3: Apesar de ser uma profissão que atualmente enfrenta grandes desafios, vejo a carreira de professor como uma das mais importantes para a sociedade; segundo o dizer "é a profissão que forma todas as outras profissões". A partir de relatos de alguns professores que já estão nesta profissão há algum tempo sabe-se que o salário não é compatível com a grande quantidade de trabalho, que a precariedade de algumas escolas da educação básica muitas vezes desestimula a prática docente assim como a falta de apoio dos familiares dos 
alunos, que nem sempre apoiam e ajudam no processo de aprendizagem dos jovens - no caso do ensino fundamental e médio. Logo, vejo o professor antes de tudo como um tipo de herói que enfrenta todas essas dificuldades a fim de mediar conhecimentos e também transmitilos.

SA4: Para mim ser professor não é apenas chegar na sala e aplicar conteúdos e provas e atividades, o professor deve entender a realidade de cada aluno, ele deve inspirar o aluno e auxilia-lo no seu desenvolvimento.

SA5: Os professore (as) são pessoas fortes, batalhadoras e criativas, sendo que, são capazes de conquistar e ser inspiração para alguns alunos. Portanto, a imagem que tenho de ser professor é de um profissional forte, porque suporta os obstáculos de uma sala de aula todos os dias.

SA6: A imagem de alguém que quer passar seus conhecimentos, um bom exemplo e que possa mudar a mentalidade dos alunos de maneira positiva.

SA7: Vejo o professor como um profissional dotado de competências múltiplas. Uma vez que, o exercício da docência no contexto contemporâneo exige que o docente se adeque as distintas situações que vão surgindo no ambiente escolar. Apesar de existir a desvalorização da profissão, o professor continua sendo aquele que forma todas as outras profissões e por isso, de fundamental importância não somente no que diz respeito à escola, mas na sociedade em geral. Pois tudo perpassa pela educação/escola e pela figura do professor.

SA8: Alguém em quem o aluno deve confiar, visto que passará para ele diversos conhecimentos adquiridos ao longo da vida e que serão de grande importância para a sua carreira profissional.

SA9: Ser professor no meu ponto de vista, é ser alguém que vai propagar o conhecimento de algo a alguém. É aquele que tem cuja responsabilidade em desenvolver o aprendizado nos indivíduos, dar conhecimento das coisas.

SA10: Profissional comprometido com o aprendizado, buscando melhorias no seu campo de atuação e sempre querendo o melhor para os alunos.

Em relação à imagem que os sujeitos-alunos têm de ser professor, o tom predominante das representações é de que ser professor é ser um "herói"/"super-herói"/"forte"/"batalhador"/"resistente" o que remete à imagem do abnegado, do injustiçado, do profissional que exerce a profissão por "amor", como um "sacerdócio", porque os salários são baixos, as condições de trabalho são inadequadas etc., ou seja, há uma representação social, portanto coletiva, de que na atualidade ser professor é uma profissão desvalorizada social e financeiramente: "ser professor continuará sendo uma profissão que carrega nas costas o peso de toda uma sociedade"; "Apesar de existir a desvalorização da 
profissão, o professor continua sendo aquele que forma todas as outras profissões [...]"; "sabe-se que o salário não é compatível com a grande quantidade de trabalho, que a precariedade de algumas escolas da educação básica muitas vezes desestimula a prática docente assim como a falta de apoio dos familiares dos alunos[...]". Essas constatações de adversidades da "vida" de ser professor constroem, portanto, uma representação de uma profissão sofrida e, pelo menos, em princípio, pouca ou nada recompensadora. A representação do super-herói remete à ideia de que ele precisa usar de muita força, ter "super poderes", para vencer situações extremamente adversas. Geralmente, o super-herói vence sozinho, age individualmente, precisa fazer por si.

Essas representações depreendidas dos enunciados são indícios que nos permitem operar com maneiras de significar a docência. Claro que não podemos afirmar que tais representações são universais no âmbito federativo do nosso país, mas nos dão pistas para refletirmos sobre os impactos dessas representações para a formação inicial e para a atuação docente na instância escolar.

A representação do professor como "herói”/"super-herói” é recorrente nas falas de SA1, SA3, SA5. Na fala de SA1 é mobilizada a representação "super-herói” para negála: "A sociedade enxergo o professor como um super herói $[\ldots] /[\ldots]$ profissão que carrega nas costas o peso de toda uma sociedade [...]". No discurso de SA3, essa representação do "herói" se dá pelo enfrentamento das dificuldades impostas pelo sistema em prol de um bem maior que é mediar e transmitir "conhecimentos": "o professor antes de tudo como um tipo de herói que enfrenta todas essas dificuldades a fim de mediar conhecimentos e também transmiti-los". Já no discurso de SA5, ainda que não haja o lexema "herói/super-herói", o campo semântico é mobilizado por meio de outros lexemas relacionados à mesma representação: “[...] a imagem que tenho de ser professor é de um profissional forte $[\ldots]$ ".

Outra representação de ser professor está relacionada ao "conhecimento" e à “aprendizagem”. Essa representação é mobilizada nas falas de SA3, SA6, SA9 e SA10. No discurso de SA3, a representação é do professor "mediador e transmissor" de conhecimen- 
tos: "mediar conhecimentos e também transmiti-los"; já no discurso de SA6, essa representação é do "passador" de conhecimentos: "passar seus conhecimentos"; e no discurso de SA9, é do "propagador/aquele que dar": "propagar o conhecimento/dar conhecimento" e que é "responsável" pela aprendizagem: "responsabilidade em desenvolver o aprendizado". Essa representação de ser comprometido com o "aprendizado" também se encontra na fala de SA10: "Profissional comprometido com o aprendizado".

Percebe-se aqui o movimento das representações de RR e de RU, pois há um jogo entre as RR sobre o professor de ser transmissor de conhecimentos e ressaltar o seu papel de mediar (RR), o uso do léxico mediar já é um indício de um conhecimento científico que se assenta no repertório representacional do sujeito em formação.

Pelo menos duas outras representações constituem os discursos dos sujeitos-alunos: a de formar outras profissões e a de ser inspiração para os alunos, como podemos ver nos excertos de SA3, SA4, SA5, SA6 e SA7.

No discurso de SA3, consta a seguinte passagem: "segundo o dizer 'é a profissão que forma todas as outras profissões"”. A recorrência de SA3 à expressão "segundo o dizer" e a frase entre aspas indicam que se trata de uma citação, de uma "verdade" já estabelecida, como um ditado popular, uma sequência formulaica, configurando-se, portanto, como senso comum, RR, de caráter inconteste, como um corolário. Da mesma forma, isso é demonstrado no discurso de SA7: "o professor continua sendo aquele que forma todas as outras profissões".

A representação do professor como inspiração para os alunos é recorrente nas falas de: SA4: "ele deve inspirar o aluno"; SA5: "ser inspiração para alguns alunos"; SA6: "um bom exemplo". No discurso de SA6, tomamos a expressão destacada como equivalente de "inspiração" motivados pelo contexto e o efeito de sentido que ela provoca: um "bom exemplo" é aquele que deve ser seguido, imitado, portanto, ele é inspirador, é modelo para o aluno se inspirar.

Como ocorrem em diversas outras passagens dos textos (que estão assinaladas em negrito), as representações que os sujeitos-alunos demonstram ter de ser professor advêm do senso comum e não de sua experiência de estudante de um curso de licenciatura em 
Letras-Português que está em fase de estágio supervisionado e a um semestre de concluílo, como na seguinte passagem da fala do SA1: "Ser professor nos dias atuais é antes de tudo um ato de resistência".

Apesar de usarem o termo "profissional": "Profissional comprometido com o aprendizado"; "[...] um profissional dotado de competências múltiplas"; "a imagem que tenho de ser professor é de um profissional forte", ele não foi usado para se referir ao profissional da educação, ao trabalhador da educação cujo objeto de trabalho é a educação, portanto, é um trabalhador como outro qualquer sujeito às intempéries (riscos) a que a profissão pode proporcionar, ou seja, não demonstram ter uma visão objetiva do papel político-socioeconômico da profissão. Isso porque ainda predomina a representação "super-herói" mobilizada pelos sujeitos-alunos.

O que nos parece, portanto, que essa representação de ser professor um "profissional", expressa pelos sujeitos-alunos, distancia-se da "formação do profissional reflexivo" pretendida por Schön (2000). Antes, prevalece uma representação de profissional idealizado no imaginário e nas crenças do que é ser professor, isto é, a representação predominante do senso comum de que é "[...] aquele que forma todas as outras profissões e por isso, de fundamental importância não somente no que diz respeito à escola, mas na sociedade em geral"; "é a profissão que forma todas as outras profissões"; "a carreira de professor como uma das mais importantes para a sociedade", ou seja, a carga de responsabilidade que recai sobre o professor é aceita de forma tácita sem, talvez, um olhar crítico, que os destinos de uma sociedade estão nas mãos do professor. Quanto a isso, pode até haver alguma crítica que aborde sobre as adversidades, mas não se percebe um posicionamento contundente sobre a questão profissional. Isso talvez diga muito de uma representação relacionada ao sacerdócio (RR), que devemos aceitar o que é colocado, o que implica na precarização da profissão. Logo, é cultivada de forma até idolatrada uma representação social "romântica" de ser professor que se perpetua desde a "professorinha" das primeiras letras.

É pertinente mostrar que a figura do professor é representada como uma profissão fundamental para o desenvolvimento de uma sociedade e o quanto ele contribui para isso, 
apesar de todas as dificuldades. Há o reconhecimento, portanto, de que ser professor: "é ser alguém que vai propagar o conhecimento de algo a alguém”; “[...] de fundamental importância não somente no que diz respeito à escola, mas na sociedade em geral”; “[...] um profissional dotado de competências múltiplas". Isso revela que os sujeitos-alunos, apesar dos pesares, guardam uma imagem positiva ainda conservada da profissão, embora esteja dento da perspectiva do senso comum, o que nos diz que esses sujeitos reproduzem aqui as representações sociais do coletivo social sobre o ser professor(a). As representações individuais que deveriam ser constituídas a partir de sua vivência como estudante do curso de licenciatura em Letras, e já no convívio de sala em decorrência do estágio, não são percebidas, no entanto, como uma construção do sujeito a partir dos conhecimentos adquiridos no decorrer do processo de formação, sob um ponto de vista técnico.

Como marcas de uma individualidade nos discursos dos sujeitos-alunos, encontramos em alguns textos marcas de primeira pessoa, como: vejo-me; vejo; para mim; tenho; no meu ponto de vista, que são posicionamentos marcados pelo ponto de vista pessoal, mas que, na verdade, não são construídos na individualidade e sim na coletividade, porque não refletem uma tomada de consciência do sujeito do que é ser professor como profissional, como trabalhador da educação; antes é a representação social já cristalizada (RR) do coletivo que prevalece.

\section{Você se vê, se identifica como professor?}

SA1: Sim. Apesar de saber que é uma profissão árdua, que exigirá muito de mim e que ao longo de minha vida profissional enfrentarei vários percalços, sim, eu me vejo e me identifico enquanto professora.

SA2: Sinceramente tenho sérias dúvidas pois, não era bem a profissão que eu gostaria de seguir.

SA3: Sim. A decisão de cursar letras foi tomada ainda quando estava concluindo o ensino médio, porém inicialmente tive algum receio de como iria conseguir lecionar em turmas tão numerosas, se conseguiria ter domínio em sala de aula, entre outras inseguranças que estão sendo combatidas na disciplina de estágio. A melhor maneira de aprender a ser professor é presenciar situações reais em sala de aula. 
SA4: Sim, apesar de essa ser uma profissão muito desvalorizada, eu ainda acredito que a educação pode transformar a vida de uma pessoa. E um bom professor pode ser alguém muito importante na vida do aluno.

SA5: Sim, desde de criança me identifico como professora, brincava de dar aula: ensinava o conteúdo que estava estudando na escola para os meus ursos, era uma forma boa de aprender o conteúdo também (os matérias que usava para dar aula era uma cerâmica branca e um pincel de quadro branco que o professor jogava no lixo). Fui crescendo e esse desejo de ensinar foi crescendo também, até o momento que entrei na [...] para o curso de Letras, que foi onde comecei a dar aula de língua espanhola, e foi neste momento ou melhor está experiência que tive na sala de aula mostrou que realmente estou no caminho certo, me identifico como professora.

SA6: Sim, espero poder conseguir contribuir de alguma forma no desenvolvimento da construção de uma sociedade que estarei a ensinar.

SA7: Sim. Antes não me enxergava muito exercendo o magistério, no entanto, através das experiências vividas ao longo da graduação e no próprio ambiente escolar, me proporcionaram obter um resultado/resposta concreta e positiva da ação docente, gerando em mim a identificação.

SA8: Sim, no entanto não tenho certeza se seguirei como professora durante toda a minha vida profissional.

SA9: Ao meu ver, ainda não me encaixei nesse plano, "Ser professor" até mesmo o próprio título de renome acadêmico ainda me soa estranho. Mas, conforme a experiência que terei no estágio talvez dê para ter certa nitidez em relação a minha formação como docente em Licenciatura.

\section{SA10: Não.}

É unânime nas falas dos sujeitos-alunos a afirmativa de que se veem, se identificam como professor(a) com exceção dos SA2 ("Sinceramente tenho sérias dúvidas"), SA9 (“Ao meu ver, ainda não me encaixei nesse plano, "Ser professor"') e SA10 (Não) que negam tal identificação de forma cabal, colocando em dúvida e dizendo não se ver (não se encaixar) nessa figura: ser professor(a). Isso provoca um estranhamento, haja vista que são alunos no sétimo semestre e eles não têm uma imagem de si como professores, o que é preocupante na medida em que os alunos das salas de aulas onde eles(as) atuaram(ão) como estagiários(as) já os veem como professores(as), pois é assim que eles se referem a quem está na posição, no papel social de quem ensina. Para essa atuação, do sujeito que ensina, invariavelmente não há outra representação social que não seja a de professor e se o sujeito- 
aluno não se vê, não se identifica com essa imagem, isso pode comprometer o seu desempenho no processo do estágio e, posteriormente, na atuação profissional docente.

No entanto, um aspecto que nos chama a atenção, é o uso das várias disjunções expressas pelos marcadores argumentativos, como: "apesar de" (duas ocorrências) e "no entanto" logo após a afirmação (sim), o que provoca um contraste marcado pela ressalva de que conhece os dissabores da profissão; pelo circunstancial de dúvida: "talvez"; e pelo circunstancial de negação: "ainda não me encaixei nesse plano", "não tenho certeza se seguirei como professora", "não era bem a profissão que eu gostaria de seguir”. Em síntese, não há uma total identificação com “ser professor” porque há incertezas em relação a seguir ou não a profissão, pois é possível que a conclusão do curso não dê essa garantia, haja vista que as incertezas são próprias da construção identitária porque o tempo todo a reformulamos.

Segundo Ribeiro (2017), ao se considerar o aspecto identitário do estagiário, é evidente que as representações veladas que são reveladas sobre o professor e o trabalho docente, ancoram-se nesse momento de passagem, de transição que é peculiar ao estágio. Portanto, refletir sobre as representações identitárias do estagiário importa para a compreensão desse fundamental momento formativo que é o término da graduação e início da prática escolar.

\section{Que conhecimentos/saberes você acha que um professor deve dominar para ser} um bom professor de Língua Portuguesa?

SA1: Leitura, escrita, conhecimento de mundo e o principal: didática.

SA2: Pra mim isso depende da área em que ele atua.

SA4: Depende muito de qual área de ensino de LP ele esta atuando.

SA5: Ter um bom domínio que prendam a atenção do aluno.

SA6: Primeiramente, conhecimento de mundo, isto é, ter na bagagem experiências já vivenciadas e respeitar as dos alunos. Em seguida ter domínio do conteúdo e postura em sala de aula. 
SA7: Acredito que o domínio didático-pedagógico seja o essencial, por mais conhecimento que o professor tenha se ele não souber transmitir, não alcançara a sua real função.

SA8: Deve conhecer essencialmente os conteúdos da língua de modo geral e ser atento as mudanças também de modo geral, nosso governo e instável e as leis mudam constantemente. Deve dominar leitura, escrita, conhecimento ortografia, gramatical, literário, enfim, deve ter uma mente aberta e focada ao mesmo tempo.

SA9: Estudar bastante, dominar o conteúdo e praticar no dia a dia.

SA10: domínio da língua, da linguagem, da gramática, e conhecimentos de didáticas.

As representações para essa questão foram as de que para ser um bom professor de Português, deve-se ter domínios diversos, inclusive sem alguma relação com língua, linguagem, gramática, leitura, escrita, literatura ou quaisquer conteúdos específicos da área de língua, linguística ou literatura. É notável que apenas três dos sujeitos-alunos (SA1, SA8, SA10) tenham mobilizados esses saberes como domínios que o professor (e de ricochete o futuro professor) de Língua Portuguesa deve ter para o seu bom desempenho como profissional.

No discurso de SA1, é mobilizada a referência a saberes de "Leitura, escrita" somente. Já na fala do SA8 os saberes mobilizados são um pouco mais abrangentes, fazendo referência ao objeto ortografia, gramática e literatura: "Deve dominar leitura, escrita, conhecimento ortografia, gramatical, literário”. Essa indicação dos saberes que o professor deve dominar para a ação docente corrobora o que o sujeito entende como a representação do que seja "[...] conhecer essencialmente os conteúdos da língua de modo geral”, ou seja, dominar "leitura e escrita" e ter conhecimentos "[de] ortografia, gramatical, literário" possivelmente são a representação dos saberes que ele compreende como "os conteúdos da língua de modo geral". E na fala de SA10, por sua vez, é mobilizado o "domínio da língua, da linguagem, da gramática" trazendo para o cenário enunciativo a representação do objeto linguagem, que não figuram nos enunciados de SA1 e SA8.

Vale salientar as representações que invocam o saber "didático" nos enunciados dos SA1, SA7 e SA10. Em SA1, saber didático é apontado como mais importante, o "principal" 
sobrepondo-se ao conhecimento e ao domínio de saberes específicos da área de conhecimento, a Língua Portuguesa: "o principal: didática". Essa mesma representação sobre o domínio do objeto "didática" é mobilizada por SA7: "Acredito que o domínio didáticopedagógico seja o essencial". Já no enunciado de SA10, os "conhecimentos de didáticas" vêm num alinhamento com os outros saberes da área de conhecimento específico, visto que está em conjunção com a ideia de adição, demonstrando que deve haver um equilíbrio entre esses conhecimentos, sem que haja sobreposição de valorização de um saber sobre outro como expressos por SA1 e SA7.

Os enunciados dos demais sujeitos-alunos não trazem representações da área de conhecimento específicas sobre os conhecimentos/saberes que um professor de português deve dominar para ser um bom professor. A maioria deles mobilizou noções vagas, imprecisas, gerais que não atendem ao comando da pergunta, o que pode demonstrar que não têm uma noção clara, do ponto de vista teórico-metodológico, do que eles precisam dominar ("levar na bagagem"), em termos de saberes e conhecimentos sobre sua área de atuação profissional, no processo de estágio e ao concluírem o curso. Então, passagens como "depende da área em que ele atua", "Depende muito de qual área de ensino de LP" podem nos indicar a imprecisão sobre o que é da competência e do domínio do profissional das Letras-Português.

\section{Considerações finais}

O corpus de análise formado com base nas respostas dos sujeitos-alunos nos permitiu constatar que dos dez informantes, três, mesmo já em processo de estágio, não se veem como futuros professores, não se identificam como professores. É bem verdade que os outros sujeitos-alunos informantes até se veem como professores, mas tal imagem se calca nas representações cunhadas pelo senso comum do sacerdócio, do super-herói, etc. e, além disso, têm uma imagem negativa do ser professor que quase sempre remetem à imagem do senso-comum: uma profissão dura, injustiçada, mas com uma missão "messiânica". A imagem do ser professor comumente representada pela imagem do "herói”/“super-herói”, 
aquele que carrega o peso de transformar a sociedade, o mundo etc., cuja missão é "mudar a sociedade" e formar "outras profissões" é que predomina.

Diante desta constatação, fica a questão: o que é preciso fazer para reverter um quadro que tem a seu favor tantas adversidades que são do conhecimento do público-alvo? Ou seja, como despertar o interesse e a motivação pela profissão entre os sujeitos-alunos do curso de Letras que já está em fase de término do curso e não se identifica com a profissão? Mesmo para aqueles que se identificam com o métier de professor, se veem desmotivados pela realidade das condições de trabalho que são oferecidas aos professores nas escolas onde eles fazem o estágio e pela realidade da clientela com a qual vão lidar em sala de aula.

E ainda tem o fator da desvalorização profissional docente: tanto financeira quanto da figura do profissional. Os baixos salários pagos e a carga horária, principalmente, em escolas privadas, e a descaracterização da autoridade do professor, apesar de ainda ser reconhecido com fundamental no processo de construção de uma sociedade, nação (como foi explicitado nos discursos do sujeitos-alunos), também pesam na desmotivação para não se veem, não se identificarem como professores atuando em sala de aula.

De forma unânime, os sujeitos-alunos informantes disseram não se sentirem seguros e preparados para assumir uma sala de aula como professores porque o que "viram" no curso, até aqui, não foi o bastante para lhes dar a segurança que eles esperavam, ou pelo menos, acreditavam que teriam ao final do curso. $E$ isso ficou evidenciado nas análises das respostas dadas pelo grupo à terceira questão: as representações sobre os conhecimentos/saberes que um professor de português deve dominar para ser um bom professor que a maioria deles mobilizou foram vagas, imprecisas, demonstrando que não têm isso de forma tão clara do ponto de vista teórico-metodológico.

Enfim, acreditamos que os resultados aqui apresentados devem nos levar a repensar o curso de formação de professores de Língua Portuguesa no sentido de refletirmos sobre o que e como está sendo ministrado em termos de conteúdo e de atualização científica teórico-metodológica e didático-pedagógica nas áreas da Linguística e da Literatura e da Educação, pelo menos, no decorrer do processo de formação inicial, para que eles tenham uma 
noção mais clara sobre que conhecimentos/saberes básicos precisam dominar para atuar na profissão com alguma segurança.

\title{
THE SOCIAL REPRESENTATIONS OF ONESELF AND BEING A TEACHER OF LETTERS STUDENTS IN INITIAL TRAINING
}

\begin{abstract}
This article aimed to analyze and discuss the social representations of oneself and of being a teacher of Portuguese Language in statements of students from the seventh semester of a Language course at a public university already in the supervised internship phase. Thus, to achieve this goal, we applied a semi-structured questionnaire to the referred students for the collection of data and formation of a corpus of analysis. The research, of a qualitative-interpretative character, had as its theoretical framework the Bakhtinian assumptions about the dialogism and the Social Representations Theory (TRS) of Moscovici $(2012,2015)$ and the studies on teacher training, based on Schön (2000) and Tardif (2014). The analyzes showed us that some students, although already in the exercise of the first supervised internship, have a representation of being a teacher as a sacrificed, unfair, but heroic profession and do not have a representation of themselves as future teachers working in the teaching profession.
\end{abstract}

KEYWORDS: Initial teacher education; Social representations; Supervised Portuguese Language Internship

\section{REFERÊNCIAS}

ABRIC, Jean-Claude. Pratiques sociales et représentations. Paris: Presses Universitaires de France, 1986..

ARANHA, A. V. S.; SOUZA, J. V. A. de. As licenciaturas na atualidade: nova crise? Educar em Revista, Curitiba, Brasil, Editora UFPR. n. 50, out./dez. 2013. p. 69-86

BAKHTIN, M. (VOLOCHÍNOV). Marxismo e filosofia da linguagem. 3. ed. São Paulo: Hucitec, 2004.

JODELET, D. O movimento de retorno ao sujeito e a abordagem das representações sociais. Sociedade e Estado. Brasília, v. 24, n. 3, p. 679-712, set./dez. 2009. p. 679-712 Disponível em: <http://www.periodicos.unb.br/index.php/estado/article/view/3090>

Acesso em: 17 abr. 2020

MARKOVÁ, Ivana. Dialogicidade e representações sociais. As dinâmicas da mente. Petrópolis: Vozes, 2006.

MATENCIO, M. L. M.; RIBEIRO, P. B. A dinâmica das e nas representações sociais: o que nos dizem os dados textuais? Estudos Linguísticos, São Paulo, 38 (3), set.-dez. 2009. p. 229-238 Disponível em: < http:// repositorio.ufc.br/bitstream/riufc/39852/1/2018_ art_pbribeirolglousada.pdf.> Acesso em: 24 ago. 2018 
MOSCOVICI, S. Representações sociais: investigações em psicologia social. 11. ed. Petrópolis: Vozes, 2015. . A psicanálise, sua imagem e seu público. Petrópolis: Vozes, 2012.

PY, B. Représentations sociales et discours. Questions épistémologiques et méthodologiques. Travaux neuchâtelois de linguistique, n. 32, Neuchâtel, Université de Neuchâtel, 2000. p. 5-20 (digitalizado)

Pour une approche linguistique des représentations sociales. In: Langages: répresentations métalinguistiques ordinaires et discours, n. 154, Paris, Larousse., 2004.

RIBEIRO, P. B.; LOUSADA, E. G. A profissão docente representada por estagiários do curso de Letras. Entrepalavras. Fortaleza, v. 8, n. 3, out-dez/2018. p. 40-62 Disponível em: <http://repositorio.ufc.br/bitstream/riufc/39852/1/2018_art_pbribeirolglousada.pdf.> Acesso em: 24 ago. 2018.

RIBEIRO, P. B.. Representações identitárias sobre o métier do professor no contexto do estágio. Veredas: Revista de Estudos Linguísticos, v. 21, 2017. p. 383-400 Disponível em: < http://www.ufff.br/revistaveredas/files/2017/11/22-Representa $\% C 3 \% A 7 \% C 3 \%$ B5esidentit\%C3\%A1 rias-sobre-o-m\%C3\%A9tier.pdf> Acesso em: 24 ago. 2018

SCHÖN, D. A. Educando o profissional reflexivo: um novo design para o ensino e a aprendizagem. trad. Roberto Cataldo Costa. Porto Alegre: Artmed, 2000.

SÊGA, R. A. O conceito de representação social nas obras de Denise Jodelet e Serge Moscovici. Anos 90, Porto Alegre, n. 13, julho de 2000. p. 128-133. Disponível em: < https://seer.ufrgs.br/anos90/article/view/6719> Acesso em: 05 out. 2018.

SILVA, K. A. Linguística aplicada, crenças e formação de professores na contemporaneidade. In: SANTOS, L. I. S.; SILVA, K. A. (orgs.). Linguagem, ciência e ensino: desafios regionais e globais. Campinas: Pontes Editores, 2013. p. 19-40.

TARDIF, M. Saberes docentes e formação profissional. 16. ed. Petrópolis: Vozes, 2014.

Recebido em: 20/05/2020.

Aprovado em: 10/06/2020. 